\title{
Promoting Critical Thinking Among Faculty About Grades $^{1}$
}

\section{James Eison ${ }^{2}$}

Southeast Missouri State University

\section{W. Lee Humphreys}

The University of Tennessee, Knoxville

\section{William M. Welty}

Pace University

Grading attitudes and behaviors have long escaped careful scrutiny by faculty, by faculty developers, and by educational researchers. For example, Geisinger (1980) has noted, "Grading is a complex activity in which all faculty participate...yet the grading of college students rarely has been investigated from the perspective of the faculty member and more information is clearly needed." While faculty teaching at a few noteworthy institutions of higher education (e.g., Alverno, Antioch, Goddard College, Hamline) might take exception to the first part of Geisinger's statement (Humphreys, Eison, \& Lindquist, 1987), Pollio and Humphreys (1989) assert that "grading outstrips both intercollegiate athletics and intramural sports as the most frequently played game on the college campus."

This paper describes three very different ways to promote critical thinking among faculty about grades. The first involves the use of the case study technique to stimulate group discussion; the second approach employs a short self-report inventory known as the Learning Orientation/Grade Orientation Scale: Form F (LOGO: F) to promote personal reflection; our third approach involves conducting an institutional "gradeuse audit." Each strategy has been field-tested on one or more occasions, 
with varying degrees of success and impact, by at least one of the three authors. On one point the experiences of the three authors are both clear and consistent: as with most faculty development activities, readers are cautioned to evaluate carefully the appropriateness each approach has for a particular campus context and climate before implementation.

\section{Using Case Studies to Stimulate Critical Thinking About Grades}

Grading is arguably the most difficult job faculty members have to do, and certainly one in which very few of us have had any training. Perhaps because of its difficulty and our lack of expertise, it is a subject that even the most well-intentioned faculty member seldom discusses with candor. Informal faculty discussions are replete with "tough talk" about grading and complaints about colleagues' lax grading habits. Yet when the pen meets the grade sheet at the end of the semester, "Rambo-graders" are few and far between and grade point averages soar higher each year.

All of which is to say that college faculty members need to do some serious critical thinking about grading - serious thinking in a context in which they feel free to share thoughts and feelings honestly with colleagues. The context must provide an environment in which faculty are unafraid to admit lack of knowledge and are unashamed to learn from peers.

Though we certainly offer no quick cure to the grading dilemmas that haunt faculty, one way to encourage a healthy interchange of ideas, to learn from each other, and to stimulate serious thought about grading is to use case studies as discussion vehicles. One aspect of case studies that makes them especially effective in stimulating critical thinking about grading is that while the problems presented in the cases are familiar to every faculty member, the protagonist in the case is another person on another campus. Thus, cases allow faculty to talk more honestly about a familiar problem because the discussions are distanced from it. Since discussions about grades often lead to self-serving chest-thumping, such distancing becomes a powerful tool for opening minds that were previously closed so as to promote fruitful discussion and ultimately help faculty members grade in a more fair and workable fashion.

There are several cases published by HBS Case Services at the Harvard Business School that deal with grading issues. Of these, two stand out in our experience as excellent vehicles for stimulating discussion, thought, and action. Bob Thompson (HBS Case Services, \#9-379-004; 
9-379-005; 9-379-006; Teaching Note \#5-384-044) is a three-part case series that portrays a young teacher who, in his first year of teaching, is confronted with a request from an African student seeking an upward revision of his final grade. The student does not challenge the fairness of Thompson's grading system, but rather appeals to his sense of justice, explaining that after years of hard work, he will not be allowed to graduate unless the grade is changed from a B- to a $B+$. The first case presents information about the teacher, the student, the class, and the institution and leaves open the question - What should Bob Thompson do? The second and third cases describe Thompson's subsequent actions.

Suzie Simons (HBS Case Services, \#9-378-033; 9-378-034; Teaching Note \#5-384-047) is a two-part case series depicting a teacher who befriends a young female student. The close relationship leads to a confession from the student that she has been handing in work prepared by her boyfriend. The teacher must decide how she will deal with the apparent plagiarism as well as with the fragile feelings of the young student - two very thorny issues.

Both of these cases have excellent teaching notes that provide plans and ideas for leading a lively and fruitful discussion that should promote clearer and more critical thinking and allow faculty members to grapple more productively with grading issues at their own institution.

\section{Using LOGO: F to Promote Critical Thinking About Grades}

LOGO: F (Eison \& Janzow, 1987; Eison, Janzow, \& Pollio, 1989) is a new 20-item questionnaire designed to assess faculty orientations towards learning (LO) and grades (GO) in the college or university classroom (see Appendix 1). The first ten survey items measure faculty attitudes; responses are recorded using a five-point Likert scale with endpoints that range from "strongly disagree" to "strongly agree." The next ten items identify alternative grading behaviors; responses are recorded using a five-point Likert scale with endpoints that range from "never" to "always" (see Appendix 2). The development and psychometric characteristics of LOGO: $F$ have been described previously (Eison \& Janzow, 1987); data from faculty groups have now been obtained on five campuses (Belmont College, Montevallo University, Sinclair Community College, Southeast Missouri State University, and Southeastern Massachusetts State University). ${ }^{3}$ 
LOGO: $\mathrm{F}$ can be used to stimulate personal reflection and critical thought among faculty in a variety of different ways; each of the three approaches requires that faculty members first complete the LOGO: F scale, which takes approximately five minutes.

\section{Using LOGO: F to Promote Group Discussion}

One obvious way to use LOGO: F to promote faculty discussion involves collecting institutional data to serve as a stimulus for group discussion. That is to say, after a questionnaire is administered to faculty across campus, a feedback form can be prepared to summarize the results in easy-to-read fashion (see Appendix 3). Based upon the results, a group facilitator or faculty developer might select several individual items to highlight for discussion. The discussion might begin by having participants predict the percentage of faculty "agreeing or agreeing strongly" with a given item and the percentage "disagreeing or disagreeing strongly" with that same item. An alternative way to start the discussion involves participants in a short writing assignment; faculty might be asked to describe, in a clear and concise fashion, their reasons for either agreeing or disagreeing with a given survey item.

Given the diversity of views commonly reported by faculty groups, the "good news" for workshop facilitators is that a lively discussion is likely to follow. The "bad news" for facilitators is that such discussions can arouse great passion among faculty; thus, discussion leaders may at times find it difficult to maintain order and to keep the discussion focused in a thoughtful and scholarly fashion.

\section{Using LOGO: F to Stimulate Debate}

An alternative workshop strategy would create a "formal debate" among faculty using a slight modification of one of the 20 survey items as the debate topic or resolution. For example, two articulate faculty members might be asked to argue the affirmative side, and two equally articulate faculty members asked to argue the negative side of the issue, "Resolved that it would be preferable to teach a course in which no grades were given than a typical graded course." An alternative debate topic might be "Resolved that grading standards should be designed primarily to challenge the brightest students in class." Based upon previous survey research, an approximately equal number of faculty could be found to support either side of these two issues. An alternative debate format would form teams comprised of one faculty member and one student. In 
either case, a public debate before an audience comprised of faculty and students is likely to generate considerable interest and enthusiasm.

\section{Using LOGO: F to Guide Instructional Design}

All too often, educational researchers ignore the practical implications of their research findings for improving the teaching/learning process. LOGO: F research, however, can readily be used to stimulate reflection on ways to enhance classroom instruction. For example, at Sinclair Community College, 59 percent of more than 380 faculty reported agreeing or agreeing strongly with the statement that "Without regularly scheduled exams, most students would not learn the material I present"; 28 percent of the faculty disagreed, or disagreed strongly with this statement. Numerous suggestions for improving student learning based upon these beliefs were generated during a group brainstorming session.

In another noteworthy finding from this same campus, only 32 percent of the respondents reported that they "design course assignments that encourage students to read outside of my discipline"; 37 percent of the faculty reported seldom or never doing so. Discussion and critical evaluation explored the possible inconsistency between their institution's goal of providing students with a high-quality general education program and the widespread use of discipline-based course assignments by faculty.

\section{Using LOGO: F to Create Cognitive Dissonance}

Cognitive dissonance, or an uncomfortable state of psychological tension, occurs whenever individuals become aware that (a) they hold two contradictory beliefs or (b) their actions are inconsistent with their beliefs. Dissonance, like hunger or thirst, motivates its own reduction; faculty made aware of dissonance-producing situations in their orientations towards learning and grades will thus be motivated to move towards consistency. LOGO: F data can be used to help faculty recognize inconsistencies in their thinking. For example, at Southeastern Massachusetts State University, 68 percent of more than 150 faculty surveyed agreed or agreed strongly with the statement "I think students should be encouraged to collaborate rather than compete"; 62 percent of these same faculty agreed or agreed strongly with the statement "I think it useful to use grades as incentives to increase student performance." Can we as faculty encourage students to collaborate rather than compete when we use grades as incentives to increase student performance? In another pair of seemingly contradictory findings, 51 percent of the faculty agreed or agreed strongly with the statement "I wish my colleagues across campus were 
tougher graders," while 54 percent of these same faculty agreed or agreed strongly with the statement "Students' concern about grades often interferes with learning in my classroom." Group discussion about these issues was reported by many faculty to be highly thought-provoking and by others to be mildly upsetting.

\section{Critical Thinking About Institutional Uses of Grades}

Individual instructors and courses do not exist as discrete entities in isolation from larger contexts or patterns of practices and values that shape them in significant ways. This is especially clear with respect to grading, where the perspectives and practices of both instructors and students are shaped by the values and practices of the specific institution of which they are a part. Colleges and universities utilize grades, and especially the grade point average (GPA), to make important decisions that both shape the lives of individual students and set a climate within institutions. It is imperative that faculty not only direct critical attention to their own grading practices and the values that define them in the context of their discrete courses, but that they give sustained and systematic consideration to the ways their colleges and universities use grades. Many students may be driven by grades, and grades may come to appear to them as isolated tokens valued independently of learning, precisely because of the important ways they are used by institutions to reward or penalize students and to advance or retard their lives.

While too often the results of first-rate research on aspects of teaching and learning in higher education seem to have little impact on faculty and administrators, such research is more difficult to ignore when grown in your own backyard. The study Making Sense of College Grades (Milton, Pollio, \& Eison, 1986) grew out of research conducted under the auspices of the Learning Research Center at the University of Tennessee, Knoxville (UTK). The study came to the attention of a number of faculty and administrators on campus, and some found its case compelling. In particular, suggestions made in that study about the, at best, limited usefulness of the GPA as a measure of student knowledge and ability caught people's attention. In light of the data used in its calculation, the GPA offers a false sense of precision and exactness, especially when carried to two or more places to the right of the decimal. The "laundering" of individual course grades into the GPA strips them of the many specific contextual factors (i.e., instructor's criteria, subject matter and level, 
nature and quality of exams) that make them meaningful symbols of communication in particular courses. That the GPA is possibly a flawed metric, or at least of limited usefulness, seemed to some to merit attention in light of the diverse uses made of it in most institutions of higher education as well as elsewhere in our society.

There was enough interest in and commitment to the assessment at UTK that a committee of faculty has been established to review and make recommendations to appropriate groups on the uses of the GPA in making decisions affecting the lives of students. Specifically, the committee has been asked to review ways the GPA is currently used and to make recommendations for limitations on its use as well as for alternative sources of information and procedures where deemed appropriate. The work of the committee has recently begun, following an initial series of conversations in which the research results and recommendations of Milton, Pollio, and Eison (1986) were discussed, often with one or more of the authors. There was certainly not unanimity among members of the committee, and "conversions" were sometimes followed by "back-sliding," but the discussions themselves made each participant more sensitive to a host of issues regarding the meaning and uses of grades; at times, these discussions were carried back to individual colleagues, departments, and other units on campus.

The list of the many ways GPA's are used within our university impressed many by its extensiveness. This list included such items as:

- Admission requirements

- College association

- Retention/Academic Review Status

- Progression through the major

- Qualification for special programs such as College Scholars, University Honors, Undergraduate Executive Program, and Tennessee Scholars Co-op opportunities

- Membership on academic committees

- Permission to take an overload

- Admission for student teaching

- Admission to some field work programs

- Dean's List

- Academic honors

- Financial aid at all levels

- Scholarships, internships, fellowships

- Eligibility for varsity athletics

- Some forms of student employment 
- Admission to graduate and professional programs

- As information sent to potential employers

Questions quickly arose about some uses, while seeking alternative sources of information and procedures demanded realistic and hard reflection. For example, grades serve as a device for sorting and classifying large numbers of students for admission into restricted programs and courses. While there may well be other more useful sources of information for making these judgments, the collection and assessment of it can involve huge amounts of time and resources. Can we really afford to interview or read statements by all who wish to major in accounting? Clearly the uses of GPA's and the issues involved will vary from one institution to another, and discussions of this sort should be quite specific to a particular college or university. Nevertheless, such areas of discussion as the following may not be atypical.

Honors (cum laude, magna cum laude, summa cum laude) at UTK have been awarded simply on the basis of overall GPA. Research by Milton, Pollio, and Eison as well as by others demonstrated that grades, and therefore GPA's, vary substantially across disciplines and colleges. Furthermore, a range of factors can have an impact on a student's program in a given term. Students often live very full lives, and they grow and change markedly through the undergraduate experience. While it is, of course, possible to dismiss academic honors as of limited importance, that may ignore their very significant symbolic value. It is potentially of the greatest importance for faculty to identify students who, in their collective judgment, merit particular attention and recognition for best representing a set of academic ideals. Discussions about how these students should be selected move easily into debates about just what qualities we most value and even on to how we can foster and facilitate those qualities in our courses. Procedural issues in selecting students for honors become issues of basic substance that cut to the heart of teaching and learning and provide a rich context for critical reflection on individual grading values and practices, as well as the uses we collectively make of grades.

It is not uncommon to find that in some institutions the possibilities for student on-campus employment are contingent on maintaining a GPA at a certain level. Given the fact that many students must or will work, on or off campus, and that a limited number of hours of work on campus seems to be related to enhanced levels of academic performance and persistence, it is possible that this criterion for on-campus employment eliminates just those students who might most benefit from part-time work experiences. Quite possibly, the effect will simply be to drive these stu- 
dents to seek employment off-campus where flexibility is sometimes reduced and more hours are demanded, and there is no possibility of coming to know other students, faculty, or staff or establishing a sense of belonging to a larger institution. Reflection on this practice provides a context for consideration of a complex range of issues regarding the relation of work and study and the integration of courses with the larger lives of students.

Changes in grading practices and, especially, in institutional uses of grades may be slow, but the results of such research as that reported in Making Sense of College Grades are ignored at a cost. On the other hand, it is not enough for individual faculty members to reflect critically only on their own grading practices. For what happens at the micro-level of the individual course and instructor is shaped in profound ways by institutional practices and the climate they create. It will be ineffective for an individual instructor to suggest that students collaborate rather than compete, when awards and rewards are being given by colleges and schools on the basis of grades earned and the GPA (converting learning into a zero-sum game); it is naive to lament that students' concerns about grades often interfere with learning when possible jobs, progression in a course of study, or prizes are essentially determined by grades and the GPA; it is simplistic to dream of deeper levels of student interest and commitment in courses in which grades are not given when institutions send so many signals that grades are the solid coin of the realm. At worst, in all these cases, such thinking and practices are unethical unless we are willing to tackle the larger world of our institutions.

The process now going on at UTK is but one model designed to illustrate that critical thinking about grades must go on both at the micro-level of the individual faculty member and his or her courses and also at the macro-level of the collegial faculty as the heart of a college or university. Practices at the macro-level set formative contexts for what is possible at the micro-levels; most important, faculty are responsible to a significant extent for what takes place at all levels.

\section{Conclusion}

Critical thinking about grades and grading practices can have substantial results and be most engaging at all levels. This article has described briefly several alternative approaches that faculty developers can take to help stimulate and initiate this long overdue critical analysis of a pervasive and sometimes perverse educational practice. The authors would be pleased to discuss these ideas further with any reader interested 
in calling or writing; in true POD spirit, we also would be eager to learn about the experiences others have had in promoting critical thinking among faculty about grades.

\section{Notes}

${ }^{1}$ This paper is based upon a symposium presented at the 1988 Professional and Organizational Development Network in Higher Education National Conference, Keystone, CO, October 1988.

${ }^{2}$ Authorship Determined Alphabetically

${ }^{3}$ Permission to use the LOGO: F questionnaire is hereby granted to all researchers who promise to report their findings to the authors.

\section{References}

Eison, J., \& Janzow, F. (1987). Understanding faculty orientations towards learning and grades. Cape Girardeau, MO: The Center for Teaching and Learning, Southeast Missouri State University.

Eison, J., Janzow, F., \& Pollio, H. (1989). The development of an inventory to assess faculty orientations towards learning and towards grades. Submitted for publication.

Geisinger, K. (1980). Who's giving all those A's? Joumal of Teacher Education, 31(2), 11-15.

HBS Case Services, Harvard Business School, Boston, MA. Bob Thompson (A, B, C) - \#9379-004; 9-379-005; 9-379-006, Teaching Note - \#5-384-044. Suzie Simons (A, B)\#9-378-033; 9-378-034, Teaching Note - \#5-384-047

Humphreys, W.L., Eison, J., \& Lindquist, J. (1987). Grades and the climate of the classroom. A symposium presented at the 12th Annual Conference of the Professional and Organizational Development Network in Higher Education, Kerrville, TX.

Milton, O., Pollio, H., \& Eison, J. (1986). Making sense of college grades. San Francisco, CA: Jossey-Bass.

Pollio, H.R., \& Humphreys, W.L. (1988). Grading students. In J. H. McMillan (Ed.), Assessing students' learning. New Directions in Teaching and Learning, 34. San Francisco, CA: Jossey-Bass. 


\section{Appendix 1 \\ LOGO: F}

\section{Part 1}

DIRECTIONS: Below is a series of statements concerning faculty reactions to students, teaching, and classroom policies. Please read each statement carefully, and indicate how strongly you agree or disagree with each item using the following scale:

(1) strongly disagree (3) neither disagree nor agree (4) agree

(2) disagree

(5) agree strongly

_1. Without regularly scheduled exams most students would not learn the material I present.

2. I think students should be encouraged to collaborate rather than compete.

3. I think college grades are good predictors of success in later life.

4. Students' concern about grades often interferes with learning in my classroom.

_5. I think it useful to use grades as incentives to increase student performance.

6. I wish my colleagues across the campus were tougher graders.

_7. I don't mind if students enroll in my classes under the "pass/fail" or "audit" options.

_8. I think my colleagues across campus place too much emphasis on using grades to motivate students.

_9. I worry about colleagues who are giving an ever-increasing number of A's and B's.

_10.I would prefer teaching a course in which no grades were given than a typical graded course. 


\section{Part 2}

DIRECTIONS: Please read each of the following statements carefully. Indicate how frequently your behavior coincides with the action described using the following rating scale.
(1) never
(3) sometimes
(4) often
(2) seldom
(5) always

_11.I set grading standards that are designed primarily to challenge the brightest students in my classes.

_12.I emphasize in my conversations with students the importance of studying to obtain "good grades."

_13. I allow students the opportunity to choose among alternative assignments as a way to enhance motivation.

_14.I encourage students to raise questions in class that are topic-related but which also go beyond the scope of the tests which I prepare.

_15.I am willing to make exceptions to stated grading criteria when unusual circumstances arise.

_16. I design course assignments that encourage students to read outside of my discipline.

_17.I orient my teaching style (e.g., content, pace, difficulty level) to satisfy the needs of upper level students (and hope that the others can keep up).

_18. I encourage students to focus primarily on their studies and to limit their participation in extracurricular activities which might jeopardize their GPA.

_19.I tell students that competition for grades prepares them for the competitive nature of adult life.

_20.I reward student improvement and growth by weighing the students' progress in my grading system. 


\section{Appendix 2}

\section{LOG0: F Scoring Directions}

Recopy your answers from the LOGO: F survey to the appropriate spaces below. Your learning orientation score is the sum of the five items which measure learning-oriented attitudes plus the sum of the five items which measure learning-oriented behaviors. Similarly, your grade orientation score is the sum of the five items which measure grade-oriented attitudes plus the sum of the five items which measure grade-oriented behaviors.

Learning-Oriented Attitudes

Item 2

Item 4 -

Item 7 -

Item 8 -

Item 10

LOA Total_

Learning-Oriented Behaviors

Item 13

Item 14

Item 15

Item 16_

Item 20

LOB Total _
Grade-Oriented Attitudes

Item 1 -
Item 3 -
Item 5 -
Item 6 -
Item 9 -
GOA Total

Grade-Oriented Behaviors

Item 11

Item 12

Item 17

Item 18

Item 19

GOB Total _

LO TOTAL (LOA PLUS LOB) =

GO TOTAL (GOA PLUS GOB) = 


\section{Appendix 3}

\section{Southeast Missouri State University Faculty Responses to LOGO: $\mathrm{F}(\mathrm{N}=\mathbf{2 5 3})$}

PART 1: ATTITUDE ITEMS

\begin{tabular}{|c|c|c|c|c|c|}
\hline \multirow[b]{2}{*}{$\begin{array}{l}\text { Item } \\
\text { Number }\end{array}$} & \multirow[b]{2}{*}{ Item } & \multicolumn{3}{|c|}{ Percentage Responding } & \multirow[t]{2}{*}{ Mean } \\
\hline & & $\begin{array}{l}\text { Disagree } \\
\text { or Disagree } \\
\text { Strongly }\end{array}$ & Neither & $\begin{array}{l}\text { Agree } \\
\text { or Agree } \\
\text { Strongly }\end{array}$ & \\
\hline
\end{tabular}

Learning-Oriented Attitudes

2 I think students should be

12.9

28.0

59.3

encouraged to collaborate

rather than compete

4 Students' concern about

31.2

18.2

50.6

3.25

grades often interferes with

learning in my classroom

$7 \quad$ I don't mind if students enroll

7.6

18.0

74.8

3.91

in my classes under the 'pass/

fail' or 'audit' options

8 I think my colleagues across

25.7

59.0

15.3

2.90

campus place too much emphasis

on using grades to motivate

students

10 I would prefer teaching a course

37.7

33.0

29.3

2.91

in which no grades were given

to a typical graded course

Grade-Oriented Attitudes

1 Without regularly scheduled

19.0

19.0

62.1

3.58

exams most students would not learn the material I present

3 I think college grades are good

28.2

35.0

36.9 
Item

Number

es as

$5 \quad$ I think it useful to use grades as $\quad \mathbf{1 7 . 6}$

20.0

Agree

or Disagree Neither or Agree

Strongly Strongly

incentives to increase student performance

6 I wish my colleagues across

59.4

29.1

the campus were tougher graders

9 I worry about colleagues who

20.1

39.0

40.9 are giving an ever-increasing number of A's and B's

\section{PART 2: BEHAVIOR ITEMS}

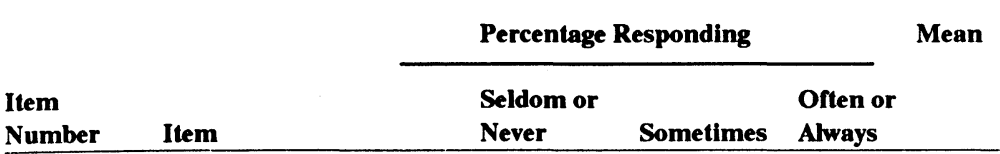

\section{Learning-Oriented Behaviors}

13 I allow students the opportunity

41.9

35.6

22.5

to choose among alternative

assignments as a way to enhance motivation

14 I encourage students to raise

questions in class that are topicrelated but which also go beyond the scope of the tests which I prepare

15 I am willing to make exceptions

to stated grading criteria when

unusual circumstances arise

16 I design course assignments that $\quad 32.4$

encourage students to read outside

of my discipline 
Percentage Responding

\begin{tabular}{|c|c|c|c|c|}
\hline $\begin{array}{l}\text { Item } \\
\text { Number }\end{array}$ & Item & $\begin{array}{l}\text { Seldom or } \\
\text { Never }\end{array}$ & Sometimes & $\begin{array}{l}\text { Orten or } \\
\text { Always }\end{array}$ \\
\hline
\end{tabular}

\section{Grade-Oriented Behaviors}

11 I set grading standards that are

35.3

30.8

34.0

2.92

designed primarily to challenge the brightest students in my classes

12 I emphasize in my conversations

43.9

24.3

31.9

2.84

with students the importance of

studying to obtain "good grades"

17 I orient my teaching style (e.g.,

52.8

34.3

12.9

2.48 content, pace, difficulty level) to satisfy the needs of upper level students (and hope that the others can keep up)

\section{Grade-Oriented Behaviors}

18 I encourage students to focus

primarily on their studies and to imit their participation in extracurricular activities which might jeopardize their GPA

19 I tell students that competition 74.7

18.6 